\title{
Acerca de las filosofías del cuidado y la potencia de la fantasía
}

\author{
Some approaches to the philosophies \\ of care and to fantasy's power ${ }^{1}$
}

\author{
Rafael Mondragón \\ Universidad Nacional Autónoma de México \\ ORCID: 0000-0003-0260-4476 \\ mondragon.rafael@gmail.com
}

\section{RESUMEN}

A partir de una confrontación con planteamientos de pensadores como Federico García Lorca, Janusz Korczak, Ernst Bloch y c. G. Jung, el texto elabora algunas reflexiones sobre la potencia de la fantasía y las enmarca en el proceso de desarrollo del niño en su primera infancia. El texto combina el análisis de planteamientos con la experiencia del autor como padre de una niña recién nacida y enmarca sus reflexiones en el marco de lo que, con Leonardo Boff, podría llamarse "filosofías del cuidado".

Palabras clave: filosofía y vida; infancia; crianza; maternidad y paternidad; nacimiento.

AbSTRACT

In the present text, the author draws from thinkers such as Federico García Lorca, Janusz Korczak, Ernst Bloch and c. G. Jung to propose some

${ }^{1}$ Investigación realizada gracias al Programa UNAM-PAIIT IN403220 "Las ciudades invisibles. La literatura como refugio en contextos de violencia”. El presente artículo es fragmento de un texto más largo. 
approaches to the power of fantasy and the origins of this power in the process of children's development. The text also makes use of the author's experience as the father of a newborn child. The approaches here presented are grouped in a field here conceptualized as "philosophies of care" using the perspective of Leonardo Boff.

Keywords: Life and filosophy; childhood; breeding; maternity and paternity; birth.

\section{RELATOS, SUEÑOS Y GENERACIONES}

En los primeros meses de la vida de mi hija, tuve la impresión de que ella aún no era un ser completamente humano. Era un animal del cosmos, que a ratos ronroneaba, a ratos ladraba suavemente. Gorjeaba como pajarito. Se comportaba como planta, como piedra. Era al mismo tiempo un ser nuevo y muy antiguo que había viajado desde hacía muy lejos. En sus primeros meses de vida, tuvimos que ayudarla con palabras a que terminara de humanizarse. El trabajo inició en su primera semana de vida, cuando le enseñamos a dormir. Probablemente antes de haber salido del cuerpo de su mamá, Sol no conocía la diferencia entre dormir y estar despierta: probablemente vivía en una duermevela ensoñada, mecida por el ritmo de la sangre de su mamá, por el palpitar, que fue el primer sonido que escuchó apenas se formó su órgano auditivo. La comida le llegaba a través del cordón umbilical, sin que Sol tuviera que pedirla. Estaba tibia, abrazada por completo. Vivía en una penumbra maternal permanente, infinita, en una relación que colorearía afectivamente todo vínculo posterior con el mundo. ${ }^{2}$

Después de haber salido del cuerpo de su mamá, Sol pasó sus primeros días exasperada: había descubierto el sueño, pero no sabía cómo dormir. Se encontró con la diferencia entre el día y la

${ }^{2}$ Para una reconstrucción de este momento imaginario, cuyas "cualidades sensibles y ensoñadas" colorean la relación posterior con el "cuerpo de palabras, acariciadas en la poesía”, así como con la realidad material en general, véase Rozitchner (2011, pp. 14, 31 y 44). 
noche, estar despierta y dormida, tener hambre o sentirse saciada. Lloraba de frustración: no entendía la sensación de estar cansada. En aquellos días, mi amigo Antonio me mandó un podcast, en donde una persona leía la famosa conferencia sobre las nanas, donde Federico García Lorca (1969) dice que, al cantar, "la madre lleva al niño fuera de sí, a la lejanía, y le hace volver a su regazo para que, cansado, descanse" (p. 156). La nana es un laberinto que la madre va tejiendo para que el niño se pierda $y$, al perderse, encuentre el sueño. Yo entendí de inmediato lo que decía porque había pasado esos primeros días cantando y poniéndole música, que, en su ritmicidad, quizá le recordaba ese ritmo originario, de ternura uteral, al que buscamos regresar constantemente a lo largo de nuestra vida. En esos días, también aprendí a cantar. Una, dos o tres coplas repetidas constantemente, y que me hacían sentir en el centro de un laberinto que iba tejiendo alrededor de ella, capa a capa, como una cebolla, espiral tras espiral. Yo, que siempre he sido malo para la música, descubrí en esos días que la palabra es, ante todo, ritmo y canto, y que ella transmite algo que es más potente que lo que comunica. Cada regreso del estribillo hacía más fuerte el tejido y permitía, como en un oleaje, el avance progresivo del sueño. Sentía cómo ella iba aprendiendo a respirar mientras me escuchaba. Ese tejido era una especie de conjuro por medio del cual yo decía algo que mi hija, llorando, se esforzaba por recoger. Ella no sabía mi idioma y yo no sabía qué era lo que le estaba diciendo, pero ambos nos entendíamos en algo que iba más allá de las palabras. Mientras escribo resuena el Cantar de los Cantares (II: 8-10): “iLa voz de mi Amado! He aquí, él viene saltando sobre los montes, brincando sobre los collados.” ¿Dónde había empezado el viaje de mi hija? ¿Qué voz la había hecho ponerse en movimiento? ¿Qué era eso que ella recogía mientras yo la llamaba, ayudándola a terminar de nacer, en esos primeros días de vida en que ella era todavía un ser del cosmos que no había aprendido el español?

En aquellos momentos, mientras tenía esas preguntas, recordé algunas palabras de Korczak (1976): 
Dices "mi hijo".

Pero no. Es un hijo común, de padre y madre, de abuelos y bisabuelos. Un "yo" lejano que dormía en la lista de los antepasados, la voz de un ataúd ya maltrecho y hace tiempo olvidado, habla de repente a través de tu hijo [...].

A veces hay niños de una sensibilidad especial que se imaginan ser huérfanos en casa de sus propios padres. La fantasía es verdadera: sus progenitores han muerto desde hace mucho tiempo [...].

El niño y la eternidad.

El niño, una partícula en el espacio infinito.

El niño, un momento en el tiempo (p. 18).

También comencé a recibir mensajes de audio, en donde amigas muy queridas cantaban canciones para Sol. Hebzoariba Hernández, que siempre ha tocado música para mí en el teléfono, tocó para ella. Y Hebe Rossell cantó una canción de cuna sefardí, de más de quinientos años de edad, que su mamá le cantaba cuando era niña. Todos regresábamos a nuestra infancia para encontrarnos con Sol. ${ }^{3}$

En los meses previos a su nacimiento, yo comencé a soñarme niño otra vez. Una amiga me dijo que eso me iba a pasar cada vez más y con más fuerza. Era como si yo mismo me estuviera preparando a recibirla en el espacio de mi propia infancia. A través de esos viajes en el tiempo, yo mismo participaba, en mi sueño, del espacio de la eternidad de donde ella venía.

Esa experiencia se hizo más fuerte en las primeras semanas de vida de Sol, porque su ciclo de sueño era muy irregular. Además, su

\footnotetext{
${ }^{3}$ En un extraordinario análisis de las estructuras subjetivas que dan pie a la vocación de cuidado en las personas que trabajan con niños, Jean-Claude Filloux (1996) escribió que "el docente tiene una relación particular con la infancia; está enamorado de su propia infancia y, al mismo tiempo, se defiende contra ella [...]; el docente es un maestro en relación con el sujeto niño al que él regresa, con el sujeto ante los sujetos niños” (p. 43). En el texto citado, el docente se vuelve una figura del cuidado y lo que Filloux dice de él vale para pensar otras profesiones, como la de trabajador social, el terapeuta o el enfermero, lo mismo que la figura originaria del cuidador en el espacio doméstico a partir de la cual estas profesiones han sido moldeadas. Añadiríamos, con Filloux, que el cuidado sólo se vuelve posible en la medida en que el docente logra "jugarse", abriéndose al fondo misterioso de la experiencia que tiene ante sus ojos y yendo más allá de sus fantasías neuróticas sobre lo que debería ser ese niño, así como de su miedo ante lo que fue su propia experiencia infantil reprimida.
} 
madre y yo estábamos poseídos por el terror: miedo de que deje de respirar, de que nos necesite y nosotros estemos dormidos. Pasamos sin dormir días enteros. Después, poco a poco, Sol fue entrando en el ciclo del tiempo de este mundo y regularizó sus ciclos de sueño. Al principio, eran ciclos breves: despertaba cada dos horas. Yo aprendí a dormir cuando ella dormía y a despertar cuando ella estaba despierta. Mis sueños se hicieron más vívidos, y empezaron a salir del territorio del sueño: a veces soñaba despierto, y los fantasmas del sueño estaban al lado mío mientras cuidaba a Sol, y no sabía en dónde estaba, si estaba vivo, si estaba durmiendo. Cantaba y me mecía con ella: aprendí que para dormirla era necesario que me acunara yo mismo también. Le cantaba al niño que vivía en mí y que se hacía presente en mis sueños.

A través de esos sueños comenzaron a visitarme personas muertas. Sobre todo, mi papá. Su presencia era constante, como si nos estuviera cuidando. Él siempre ha tenido maneras de hacerse presente. Una vez, cuando Laura ya estaba embarazada, tuvimos una larga videollamada con la familia de mi hermano mayor, que vive en Chile. Yo les había propuesto un juego: nos juntaríamos a contarnos historias. Mi hermano se tomó el juego muy en serio: había preparado una historia, la había ensayado junto a sus hijos. Comenzó a contarla. Era una historia extraordinaria, que se alargaba y se retorcía. Estaba llena de momentos sorprendentes. Laura y yo no podíamos creerlo. Estábamos asombrados. Terminó y le preguntamos de dónde había sacado esa historia. Él se sorprendió: nos dijo que era una historia mexicana, que nosotros debíamos de conocerla. No la conocíamos. Le dijimos que de dónde la había sacado. Él nos dijo: de este libro que compré cuando estuve allá. Eran los cuentos populares mexicanos, editados por Fabio Morábito en el Fondo de Cultura Económica. Esa tarde mi hermano había sacado el libro en busca de un cuento para preparar y había abierto el libro al azar. Le pedí que buscara la nota al final del libro, donde venía la fuente del cuento. Mi hermano lo hizo y me dijo: ese cuento lo escribiste tú en un libro llamado Cuentos del general grillo, de 1983. Yo le dije que no podía haber escrito ese cuento porque nací, justamente, en 1983. Era un cuento de mi papá, que se 
llamaba como yo. La hija adolescente de mi hermano abrió la boca en un gesto de asombro. Le dije: ¿te das cuenta de lo que acaba de pasar? Tu abuelo acaba de contarnos un cuento a través de tu papá. Pero no sólo eso: Sol ya está aquí. Ella escucha todo desde la panza de su mamá. Reacciona a las historias y la música. Tu abuelo acaba de contarle a Sol un cuento a través de tu papá. Ese día sentí con mucha fuerza la forma en que los hijos vienen de la eternidad y son llamados con palabras por personas que habitan en el pasado infinito: mi papá recogió esa historia en Chiapas, de una persona que la había escuchado de alguien más. Un investigador del Instituto de Investigaciones Filológicas volvió a contar la historia y luego mi hermano la tomó del libro de ese investigador y la rehízo, para contárnosla a nosotros; y Sol la escuchó. Cada uno de nosotros era un instante en el tiempo, pero la voz fue pasando a lo largo de las generaciones, jalándonos como si fuéramos las cuentas que alguien enhebra en un collar.

Antes de nacer, Sol se fue apareciendo en los sueños de amigos y conocidos. Daniel Goldin nos dijo: la acabo de soñar. Es una niña. Su mamá y yo la fuimos presintiendo antes de que estuviera con nosotros. En aquellos días, recordé al profeta Jeremías (I, 5), con su experiencia de un Dios femenino y maternal, que le declara haberlo conocido así, como conocen las madres antes de que sus hijos hayan nacido, sólo por presentimientos: "antes de que te formaras en el vientre de tu madre te conocí."

Todas estas experiencias, que competen al poder de la palabra, del relato y del canto, pero también -y sobre todo- remiten a la magia, a los enigmas que se muestran en los sueños y a la presencia de la eternidad en las generaciones, se vinculan también, para mí, con un misterio mayor: cómo es posible que, en medio de una catástrofe general como la que estamos viviendo, la vida se renueve, los niños nazcan, las plantas crezcan, los pájaros canten y hayan retomado la ciudad. El misterio de un mundo que comienza al día siguiente en que un mundo entero ha terminado. La resurrección de la vida y el llamado que va, de eternidad a eternidad, del pasado infinito al futuro ilimitado, a través del collar de cuentas de las generaciones en que estamos enhebrados. 


\section{El REFUGIO DE LA FANTASÍA}

Mientras escribo, retorno a mi historial de You'Tube para escuchar de nuevo la música que le puse a Sol en esos primeros días. En aquellos momentos, la necesidad de sueño me hizo encontrarme, sin querer, con una comunidad de desconocidos: insomnes, personas que habían perdido a seres queridos, personas que recordaban, personas que habitaban la belleza o buscaban un momento de paz. Hay muchas historias de amor. Una mujer cuenta: "Por más de cuarenta años, mi esposo ponía esta música para cuando hacíamos el amor. Él murió el 25 de octubre de 2020. Hoy es su cumpleaños y he estado escuchando a Satie toda la tarde; no pude hacerlo antes del día de hoy. Hoy estamos sentados aquí las fotos de él y yo." Otra dice: "Recuerdo que tocaba esta canción cada noche, durante un invierno entero, hace dos años. Esta canción se convirtió en mi hogar y en el único lugar donde podía encontrar humanidad" (Maité Liébana). Un hombre añade:

Cuando mi padre falleció en un hospicio, el año pasado, yo estaba solo con él. Mientras esperaba a que mi familia llegara al hospital, puse esta canción, este video. Lo repetí una y otra vez. Me mantuvo calmado y cuerdo y así pude pasar un tiempo tranquilo con mi padre antes de que llegara mi familia y comenzara la realidad de perder a un ser amado" (Andrew White).

Un joven confiesa: "Estaba en mi cama, sin poder sentir mucho. Pero después de escuchar esta canción siento la necesidad de salir y hacer algo que sea bueno para mi cuerpo" (raarnt). Otro joven añade: "La vida es tan corta. Creo que sólo viajaré sin compañía, lo haré mientras siga siendo joven" (Kie). Una mujer recuerda: "Mi hermana tocaba esta pieza hace muchos, muchos años. Cada vez que la escucho desaparecen las barreras de la distancia y el tiempo, y una vez más estoy estudiando en la mesa del comedor, mientras escucho cómo esta pieza se despliega” (Helen Wright). Y después añade otra mujer: "Cuando era una pequeña niña, en un pueblecito llamado Balimbingan, mi papi tocaba esta música clásica. Ahora 
trato de disfrutarla mientras tomo un té caliente y recuerdo a mi papá (Meirita Nasution). ${ }^{4}$

A lo largo de la pandemia, pensé mucho en la fuerza que regala la fantasía. Antes del nacimiento de Sol, animé, en la pandemia, espacios donde nos contábamos cuentos, cantábamos canciones y compartíamos secretos. Era una forma de consolarnos, al tiempo que un trabajo de investigación participativa sobre la potencia de la literatura en contextos de crisis mundial. Animé círculos de lectura y trencé, vía telefónica, una red de desconocidos, en distintos lugares del mundo, que se regalaban mutuamente canciones, poemas y relatos, en una relación uno a uno. Ese experimento se llamó \#CiudadesInvisibles y comenzaba con una consigna aparentemente sencilla: una invitación personal a regalar una canción, un poema o un relato a alguien que no conocías, pero podía estar necesitándolo. Una invitación así de amplia llevó a que una persona cantara a la mitad de la noche; a que otra contara el cuento que hacía fuerte a su niño; a que otra más recitara un poema; otra un conjuro de María Sabina; otra leyera una historia de dragones que acababa de escribir. Se escuchaban los llantos de los niños, el sonido de la lluvia; se sentía el calor de cada cuerpo, cada voz. Yo funcioné de mediador: fui trenzando los puentes que permitían que el audio de uno le llegara al otro, de forma que cada vez que un nuevo desconocido respondía a mi petición, en agradecimiento yo le mandaba la voz de uno, dos, cuatro desconocidos que respondían. Y guardaba registro de lo que ocurría en ese ejercicio que trataba de crear para las palabras una gigantesca caja de resonancia. Para curarnos del espanto, era necesario crear un espacio gigantesco de escucha, en donde las palabras pudieran resonar; un refugio donde reencontrar la humanidad perdida.

En el transcurso de ese y otros ejercicios, comencé a escribir para mi bebé, que se asomaba en la panza de su mamá. Al mismo tiempo, se fueron muriendo, uno tras otro, amigos imprescindibles. Hubo un momento en que se acumularon tantas muertes que mi

${ }^{4}$ Estos y otros testimonios pueden verse en la sección de comentarios de los videos de Logansaan (2012) y Eduardo André (2019). La traducción de todos ellos es mía. 
cuerpo se paralizó de dolor; estuve en cama casi dos meses. Ricardo Melgar Bao sobrevivió al Covid, pero quedó lastimado de sus pulmones. Tuvimos una última y muy breve conversación, porque le cansaba tanto respirar que ni siquiera podía sostener las palabras. No dejó de mandarme poemas que transcribía desde su celular, casi hasta el último día. También me mandó, a mí y a un grupo de amigos, un hermoso ensayo que escribió y trataba sobre el poder de la vida y la experiencia de sobrevivir. Murió Tobi, el mítico bibliotecario anarcopunk que guardaba el tesoro dejado por el anarquista español Ricardo Mestre en la Biblioteca Social Reconstruir. Murió Rodrigo de Gardenia, muy joven, con tres hijas -la más joven tenía seis meses cuando su papá murió de Covid. Aún no sé qué pasó con la extraordinaria biblioteca comunitaria que construyó en la Magdalena Contreras. No he tenido fuerza para preguntar. Murió Néstor Ramírez Peña, mi amigo extraordinario, el narrador que construyó en su casa una de las bibliotecas comunitarias más potentes de este país. Esa biblioteca era el epicentro de la fiesta del día de muertos en Santiago Zapotitlán. Todo el pueblo llegaba a su casa, en donde se ponía un altar, se hacía fiesta, se leía en voz alta y se contaban cuentos. En el momento máximo de la fiesta, Néstor aparecía convertido en su alter ego, Frida Gaultier, una mujer que se disfrazaba de catrina y vestida de gala leía cuentos en voz alta.

Néstor fue el último de mis amigos en leer en voz alta para \#CiudadesInvisibles. Su audio se quedó grabado en mi computadora hasta el día de ayer. Los amigos y familiares de Néstor llevaban una semana buscándome, porque se iba a hacer la fiesta de muertos en honor a él y nos estaban invitando a formar parte de ella. Yo no respondía las llamadas: sentía que no tenía fuerzas. Sus amigos y familiares estábamos reunidos en un grupo de WhatsApp. Ayer les escribí. Les conté que Néstor me ha visitado en sueños. En el último de ellos, tuvimos una larga conversación. Estábamos muy felices, pero en algún momento nos pusimos tristes, pues acabábamos de darnos cuenta de que él estaba muerto. Sabía, por algunas conversaciones, que yo no era el único a quien Néstor visitaba en los sueños. Sentía que, a través mío, Néstor quería contarles un 
relato. Así que les mandé el audio que él me había dado para que lo pudieran escuchar.

\section{FUEGO, MEMORIA Y RITMO}

Recuerdo que cuando Sol se estaba formando en el vientre de su mamá, la filósofa Tatiana Aguilar-Álvarez Bay nos dijo: "No tienen de qué preocuparse. No tienen que hacer nada. Sol es como un bollo que se está haciendo en la panza de su mamá." A partir de ese momento, le pusimos a nuestra hija el apodo de "bollito"; y la imagen de la panza de Laura convertida en horno que hace madurar la vida me comenzó a perseguir. Muchas semanas después recordé un texto enigmático de C. G. Jung.

En Símbolos de transformación, Jung (2012) describe esa primera actividad voluntaria que es el acto de mamar leche cuando se es muy pequeño: en la succión, está la presencia de un ritmo que excede la mera función alimenticia y en donde aparece, por primera vez, la libido, energía vital que después coloreará la sexualidad, permitirá crear un vínculo con el mundo exterior e "investirá" las actividades de cultura, la experiencia subjetiva y el trabajo de simbolización. El ritmo de la boca que succiona evoca un ritmo fundamental, el primero que escuchó en el horno del cuerpo de su mamá: se moverá desde la boca hacia el resto del cuerpo, invistiendo energéticamente los brazos y las piernas y ayudando a la construcción de los primeros gestos no conscientes que ocurren en el momento de la succión, como el rascar, el hurgar y el pellizcar con las manos. Gestos posteriores en el mundo del trabajo, la música y la danza reactualizan ese gesto rítmico originario y les dan a esos mundos su poder de seducción, pues "el ritmo constituye un carácter específico de todos los procesos emocionales en cuanto tales" (p. 173).

Jung (2012) vincula este ritmo originante con las primeras experiencias del lenguaje, sobre todo con ese lenguaje poético que está coloreado afectivamente y se canta para dormir a los niños. Muestra cómo esas experiencias han sido dibujadas en distintas mitologías a partir del simbolismo del fuego, pues en la raíz de los nombres de los héroes que regalan el fuego hay usualmente 
palabras que remiten a la acción de frotar. El frotar rítmicamente, que permite la aparición del fuego, se vincula a esa fuerza afectiva que permite empalabrar el mundo y la presencia, en distintas tradiciones mitológicas, de raíces vinculadas a la acción de frotar en los nombres de las deidades que descubren el fuego hacen a Jung escribir que "de acuerdo al material que obra en nuestras manos, no parece que haya que excluir que haya sido de esta manera como se descubrió la generación del fuego, es decir, mediante la reactivación regresiva del ritmo" (p. 172).

Una noche en que Sol y yo estábamos especialmente desesperados, porque ella no se podía dormir, sin saber cómo, comencé a cantar una canción que no sabía que sabía. Ella surgió naturalmente, con todo y sus palabras Me di cuenta que probablemente estaba cantando algo que me habían cantado cuando tenía la edad de Sol.

\section{UNA ÉPICA CALLADA}

Antes de morir, la gran escritora de ciencia ficción Ursula K. Le Guin escribió una novela, Lavinia, en donde le da voz a una mujer, un personaje secundario en el poema de Virgilio, que se casaría con Eneas. En su novela, Le Guin permite que Lavinia se encuentre con la sombra de Virgilio, para conversar con él. Es una conversación amorosa, no exenta de sentido crítico, en donde Lavinia acusa a Virgilio de haber hecho con su poema una alabanza del asesinato:

-¿Por qué [tu héroe] mata como un carnicero?

-Porque hace lo que tiene que hacer.

- ¿Por qué tiene que matar hombres indefensos?

-Porque así es como se fundan los imperios. $\mathrm{O}$ al menos espero que así lo entienda Augusto. Pero no creo que lo haga (Le Guin, 2018, p. 105).

En otro momento, Lavinia le dice:

-Si la crueldad procede de la debilidad, tal como dijiste, debes de ser muy débil -dije.

No respondió.

Al cabo de un largo rato, añadí: 
-Yo creo que eres fuerte.

Mis labios y mi voz temblaban al decirlo, porque, sin desearlo, sentía lástima por él y tenía el corazón lleno de lágrimas (Le Guin, 2018, p. 76).

Cuando leí este libro de Le Guin encontré palabras para una sensación que tuve los días después del nacimiento de Sol. Mi familia me llamó desde Chile para preguntarme cómo estaba. Yo dije que "bien". No me creyeron. Es que yo mismo habitaba, al mismo tiempo, en este mundo y en otro; estaba dedicado por completo a sostener la vida de esa persona que acababa de nacer. Le conté a mi cuñada Paloma cómo habían sido esas largas horas, la violencia extrema del nacimiento, su crueldad y su ternura. No entendía por qué las personas no hablamos todo el tiempo de los partos. Le dije: tengo la sensación de que los varones inventamos la épica porque no podemos dar a luz.

\section{SECRETO, INICIACIÓN Y FANTASÍA}

Sol va creciendo y construyendo, poco a poco, su autonomía. Va ganando control de su cuerpo: comienza con las manos, que mueve con delicadeza, como si fueran herramientas. Después baja hacia la columna; y poco a poco, a las piernas. Comienza a gatear. $\mathrm{Me}$ necesita menos: va ganándose el derecho de decidir a dónde quiere ir. Huye de mí: se esconde debajo de la mesa. Sabe que ese lugar está prohibido, pero igual se mete. Es un lugar secreto, donde ella puede estar consigo misma. Bloch (2007) decía: es el deseo de estar, no sólo "consigo mismo", sino "entre sí". Ese deseo de buscar espacios secretos, donde sustraerse de la mirada adulta, explica, después, para Bloch la fascinación infantil por los barcos, las carpas de circo y los vagones de feria: refugios móviles que prometen la lejanía y lo desconocido, hacen soñar una huida que llevarán al descubrimiento de uno mismo: "El niño escondido se escapa también, medrosamente. Busca lejanos horizontes, a pesar de que se encapsula; se tiene a sí mismo sólo cuando se escapa, siempre armado de sus cuatro paredes" (p. 49). La fantasía, en ese caso, no es 
sino una fuerza sin figura; una promesa que hace imaginar y soñar; y que despierta vagos anhelos y el presentimiento de una potencia.

También está esa sombra de fantasía que Bloch (2007) describe en relación al deseo de hurgar en las cosas preciosas para intentar encontrar en ellas eso maravilloso que se asoma. Cuando salimos a caminar los tres, la mamá de Sol va poniendo en la carriola flores que corta para ella, pequeñas ofrendas, tesoros. Sol las toma, con sus manos delicadas, que aún no termina de controlar. Rompe la flor, buscando la presencia que se asoma en ella. No la encuentra y gruñe, decepcionada. También derriba las torres de madera que pacientemente construyo para ella, con sus juguetes. No tiene aún la habilidad para construir, pero sí el gesto que destruye y que al destruir pareciera intentar descorrer un velo:

Un niño echa mano a todo para saber lo que significa. Lo tira todo, posee una curiosidad insaciable, y no sabe de qué. Pero ya aquí vive lo fresco, ese algo distinto con el que se sueña. Los niños destruyen lo que se les regala, buscan algo más, lo desencubren. Nadie podría decir de qué se trata, y nadie lo ha recibido. Así se desliza lo nuestro; todavía no existe (Bloch, 2007, p. 47).

La realidad es ominosa y debajo de ella late un secreto que se escapa. Los objetos en que se asoma el secreto hacen, también ellos, soñar.

$\mathrm{Al}$ mismo tiempo, las canciones van dando pie a los relatos. Me observa con mucha atención cuando hago hablar a los títeres, a los juguetes, o invoco la voz que está guardada en sus libros al leer en voz alta. Imita los sonidos de los animales que presento en las historias. El que más le importa es el león: aprende a rugir como él. Luego, en el parque, ruge de alegría al encontrar a un niño. Se ha vuelto ella misma un león. Después la sorprendo en momentos en que está "entre sî" y hace hablar, ella misma, a sus juguetes, o tiene largos monólogos con sus libros abiertos. Hace unos días Sol ha comenzado a hablar con las cosas de la casa: después de caerse, regaña al suelo, se pelea con la silla o balbucea frente a la foto de su abuelo muerto. Este despertar a la dimensión ominosa de los objetos vivos es, para mí, parte de una misma experiencia, que se 
vincula a la capacidad de hablar con los juguetes y, también, al acompañamiento de una voz maternal o paternal que late inscrita en los libros que hemos contado o leído en voz alta.

-¿Pero se debería forzosamente pasar por el libro para contarle esas historias a los bebés? ¿Y el trabajo de los cuentacuentos?

-Yo aprecio mucho a los cuentacuentos, pero en ACCES nuestra posición es un poco diferente de la de ellos. El que lee aparece como el narrador de un texto, su contar está ligado a su persona, ciertos contadores ofrecen el sentimiento de inventar la historia que están contando. Pero lo escrito tiene un estatus muy particular para el niño: se liga al soporte-libro que garantiza la repetición exacta de la historia que podría llegar a ocurrir dentro de un día, un mes, un año...

${ }_{-i}$ Fidelidad al texto, fidelidad del texto!

-Y a través de ella, la fidelidad, la estabilidad, la persistencia de las personas amadas que vuelven a contar la historia del libro. Si el texto cambia de una tarde a la otra, ¿qué podrá garantizarle al niño angustiado por la necesaria separación nocturna que su padre o su madre no cambiarán la siguiente mañana?

-Los besos, las palabritas que se regalan en el momento de despedirlos en la cama, ¿ellas no son suficientes?

-No son suficientes para luchar contra la angustia de la muerte, que comienza a partir del tercer año de vida. Enfrentados a ese miedo a morir, ese miedo de que los padres mueran, se observa un fenómeno extraño: sólo una historia ficticia vuelta a contar, un relato donde hay una lengua con una estructura por completo diferente a la del habla liberada en la vida cotidiana, parecer tener un efecto contra cierta angustia de la separación. La lengua del relato permite soportar mejor la ausencia, y dominar las representaciones ligadas al objeto ausente.

-Cuando hablas de volver a contar el escrito, ¿estás hablando de cualquier escrito, de los "escritos funcionales" por ejemplo, los que se pueden leer en el ambiente cotidiano, en la realidad ambiente del niño?

-No, se debe comenzar por lo imaginario. Muchos maestros han pensado esto, y lo siguen pensando, de una manera utilitarista. Es todo lo contrario a lo que observamos: para comenzar a tratar la 
realidad ambiente, se debe comenzar por la realidad imaginaria [...]. No se puede abordar el materialismo dialéctico, sino después de largos años de poesía. No se les puede interesar en su ambiente en el aspecto realista con el proyecto de modificarlo, sino después de un largo pasaje por el imaginario, por el placer del texto, donde todo lo que existe aparece bajo el punto de vista del funcionamiento de la mente y de la capacidad de pensar.

- ¿La capacidad de pensar?

-Ser capaz de pensar, de imaginar un proyecto, ser capaz de descansar en uno mismo el tiempo que sea necesario y sin angustia, y por tanto, tener un aparato físico que funciona bien.

- ¿Los grandes inventores, los grandes sabios no han sido, por tanto, primero los soñadores, los poetas?

-Y lo siguen siendo. Los sabios auténticos con los que me he encontrado practican la poesía, la música, la pintura, de una manera bastante intensa (Zucca, 2003, pp. 122-123). ${ }^{5}$

Lo que acabo de citar son fragmentos de un diálogo con René Diatkine, el pensador y psicoanalista francés que, junto a sus amigas, fundó A.C.C.E.s., una biblioteca para bebés, que trabaja con los hijos de migrantes y trabajadores, con el objeto explícito de poner a disposición historias que ejercitan el poder de fantasía de los niños; y así los preparan para enfrentar la segregación y la exclusión. Un lugar en donde se les permite entrar en contacto con los libros y se lee en voz alta y donde la militancia comunista de algunos de sus fundadores ha dado paso a un trabajo con la palabra, la metáfora y el relato que intenta crear situaciones de mediación que alimentan la fantasía y la capacidad subjetiva de enfrentar la segregación y la exclusión.

El diálogo de Sol con sus muñecos y sus libros comenzó a ocurrir más o menos al mismo tiempo en que ella aprendió a guardar secretos: antes, cuando iba a hacer una travesura, la escuchábamos reírse en voz alta, como si fuera un duendecito. Ahora ha aprendido a callarse la risa, para que no la encontremos, casi al mismo tiempo en que aprendió a contar cuentos para ella misma.

\footnotetext{
${ }^{5}$ La traducción es mía.
} 
Esa cualidad ominosa se extiende hacia algunas personas. Hace unos días, al caminar, nos encontramos con un hombre diablesco. Ellos aparecen de vez en cuando. Esta vez era un vagabundo. Llegó en bicicleta, tocó el timbre antes de bajar, se sentó en la banca de enfrente de donde Sol y yo estábamos sentados. Todos los dientes superiores se le habían caído y los de abajo estaban amontonados unos con otros; producían la impresión de un montón de colmillos afilados. Su cubrebocas era de la radio de la Universidad Iberoamericana. Su maletín, viejo y protegido con una bolsa de lona, era de la Comisión Nacional de Derechos Humanos. Todo parecía regalado. Sonrió. Se alisó el cuello de la gabardina como si fuera un presentador de feria. La ropa le quedaba grande. Sacó un viejo termo de café y una torta guardada en una bolsa de plástico. Cruzó una pierna y comenzó a conversar con nosotros. Dijo que era un día estupendo. Me habló de su hija y de cómo ella era lo más importante en su vida. Me dijo, con un gesto misterioso: "Te diré como se llama ella si me dices cómo se llama la tuya." Le dije que Sol y él asintió: ¡Ella es un Sol! ¡Lo ilumina todo! Me dijo que su hija se llamaba Sofía Paloma. Su madre le puso Sofía; él, Paloma, porque la niña nació en Jueves Santo, en una noche de luna llena... Cuando el Espíritu del Señor baja a la tierra y nos llena a todos. Mi hija en ese momento empezó a pedir que nos fuéramos. Me despedí y dije que ella ya tenía sueño. Nos fuimos mientras el vagabundo diablesco se comía su comida. Sol había querido irse, pero mientras nos alejábamos no lo dejaba de ver. Son esos seres ominosos, aterradores, que son heraldos de la fantasía, iniciadores en otra realidad, que pone en riesgo la nuestra. Guardan secretos que a la vez tientan y amenazan.

LA POTENCIA DE LA FANTASÍA EN EL MARCO

DE LAS FILOSOFÍAS DEL CUIDADO

Hace algún tiempo me encontré con estas palabras de Marguerite Yourcenar en un texto inédito de Tatiana Aguilar-Álvarez Bay:

He reflexionado con frecuencia acerca de lo que podría ser la educación del niño. [...]. Se intentaría familiarizarlo a la vez con los li- 
bros y con las cosas [...]; aprendería a dar los primeros auxilios a los heridos; su educación sexual comprendería su presencia en un parto, su educación mental la vista de enfermos graves y de muertos.

La experiencia del nacimiento es fundacional porque todos nacimos de otra persona, fuimos nacidos en un cuerpo de mujer; y sin embargo, la conversación sobre él no es algo que ocurra a menudo. Se nos oculta esa condición de haber nacido, como se ocultan las muertes y las enfermedades, todas cosas vergonzosas. En las antípodas de esa actitud, Mircea Eliade escribió repetidas veces que la experiencia del nacimiento era el modelo básico en torno del cual se construyen los rituales de cultura; y que en ese sentido la vida humana podía entenderse como una sucesión interminable de momentos donde se nacía y se volvía a nacer. La experiencia del nacimiento, a su vez, remite de manera fundamental al cuidado, entendido como modo de ser fundamental que permite el sostenimiento de la vida, al tiempo que permite la estructuración de lo humano. El ser humano que no recibe cuidado se desestructura, se debilita, pierde sentido y muere; el que no aprende a hacer las cosas con cuidado, reviviendo en su vida cotidiana el cuidado que recibió, termina por dañarse a sí mismo y por destruir lo que se encuentra a su alrededor. El gran teólogo brasileño Leonardo Boff ha recordado que el cuidado no es, por ello, un tema entre otros, sino una realidad fundamental, que se vuelve fenómeno en nuestra conciencia, se muestra en nuestra experiencia y moldea nuestra práctica. Por ello, "no se trata de pensar y hablar sobre el cuidado como si se tratara de un objeto independiente de nosotros, sino de pensar y hablar a partir del cuidado como es vivido y se estructura en nosotros mismos" (Boff, 2002, pp. 32 y 89).

Yo creo que la experiencia del nacimiento y del cuidado también pueden decir algunas cosas sobre la fuerza de la fantasía. Para hablar de ella, yo sólo puedo usar la primera persona, pues las cosas que he aprendido de este tema me fueron enseñados por mi hija en este tiempo de paso, donde, como dijo Laura, mamá de Sol, en su última pieza teatral, nuestra hija nos hizo nacer de nuevo, al tiempo que nacía de su madre (García, 2021). 
BLOCH, E. (2007). El principio esperanza 1. Madrid: Trotta.

Boff, L. (2002). Cuidar la tierra. México: Dabar.

Eduardo André. (10 de noviembre de 2019). Arvo Pärt- "Spiegel Im Spiegel”. Youtube. <https://www.youtube.com/watch?v=91AgJcyt4yQ\&t=2650s $>$.

FIlloux, J. C. (1996). Intersubjetividad y formación. (El retorno sobre sí mismo). Buenos Aires: Novedades Educativas-Universidad de Buenos Aires.

García, L. (2021). Carta al sol. Youtube. <https://www.youtube. $\mathrm{com} /$ watch?v $=\mathrm{C} 9 \mathrm{y} 2 \mathrm{yCv} 9 \mathrm{IGE}>$.

García Lorca, F. (1969). Prosas. Madrid: Alianza.

Jung, C. G. (2012). Simbolos de transformación. Madrid: Trotta.

Korczak, J. (1976). Cómo hay que amar a un niño. Madrid: Sociedad de Educación Atenas.

Le Guin, U. K. (2018). Lavinia. Buenos Aires: Minotauro.

LogansaAn. (28 de octubre de 2012). Erik Satie Once Upon A Time In Paris (Artwork by Edouard Leon Cortes). Youtube. <https:// www.youtube.com/watch?v=b9WKC5s'T9Z4>.

Rozitchner, L. (2011). Materialismo ensoñado. Ensayos. Buenos Aires: Tinta Limón.

Zucca, N. (2003). Pas de solfège sans musique. Une interview de René Diatkine En Les cabiers A.C.C.E.S. Tolouse: A.C.C.E.S. 